\title{
Science and law enforcement teaming up to help "critters"
}

\section{An interview with Scott Bauer, Senior Environmental Scientist, California Department of Fish and Wildlife}

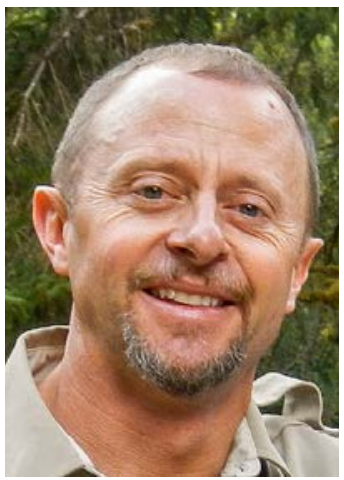

Scott Bauer
C alifornia's legal cannabis market is regulated by a suite of state agencies that follow the plant on its journey from cultivation site to manufacturing facility to ultimate point of sale. But a special role is played by three Watershed Enforcement Teams which, operating within the California Department of Fish and Wildlife (CDFW), work in cannabis-growing regions to protect native plant and wildlife species from practices such as illegal stream diversions, habitat destruction and illegal use of pesticides. Scott Bauer, a senior environmental scientist with the CDFW, works on one of these teams.

\section{How would you describe a typical day's work as a member of a Watershed Enforcement Team?}

The Watershed Enforcement Team focuses on cannabis-related violations of the Fish and Game Code - for example, people illegally diverting water from streams or lakes, or causing dirt to enter the stream. We focus on both compliant and noncompliant cannabis sites, but mainly black-market cultivation sites. We have three teams across the state, and our goal is to protect the environment.

Each team is composed of scientists and wildlife officers. Our scientists spend a lot of time looking at watersheds with cannabis cultivation and deciding how we should focus our efforts - how to get a game plan ready for subsequent enforcement. We look at watersheds that have a lot of sensitive natural resources, such as salmon and steelhead, or Northern spotted owls. We have experience in a big variety of biological and physical sciences. Depending on the site we're going to, we [might] need a geologist or an aquatic toxicologist or what have you. My team operates in Humboldt, Del Norte and Trinity counties - basically, the Emerald Triangle - and I have a herpetologist, a hydrologist, a wildlife management person and a natural resource management person.

A lot of us have been involved in this issue for years and have been to hundreds of sites. We know what to look for, where the violations will occur and what the impacts are. We've all been trained in environmental impact assessment. We use those backgrounds to help develop strong cases, to figure out how to remediate sites and do restoration of sites. When it comes to actual enforcement, we document violations and write reports, which hopefully causes people to get into compliance. Or, if it's a black-market site, we write environmental documents to help support the court case when needed. We [scientists] document the environmental crimes. The law enforcement [people] do the cases.

\section{Would you say the environmental problems associated with unlicensed cannabis cultivation, such as illegal water diversions and irresponsible use of pesticides, are getting better or worse in the Proposition 64 era?}

Well, it's a good question. There are thousands of people applying for licenses around the state, and that's a great thing. People are coming into compliance. [Compared to] when we started this enforcement team 4 or 5 years ago, it's a different world. The majority of the people [at that time] were not in the system, not actively pursuing a legitimate site.

It's so fluid right now. We still have black-market sites, and they're still abundant, and we've been to a few sites in the past year where we [found] a banned pesticide, carbofuran, which we hadn't seen before on private-land cultivation sites. We still go out and find really egregious sites. I think our team alone did 150 enforcement actions last year, so there's plenty of work

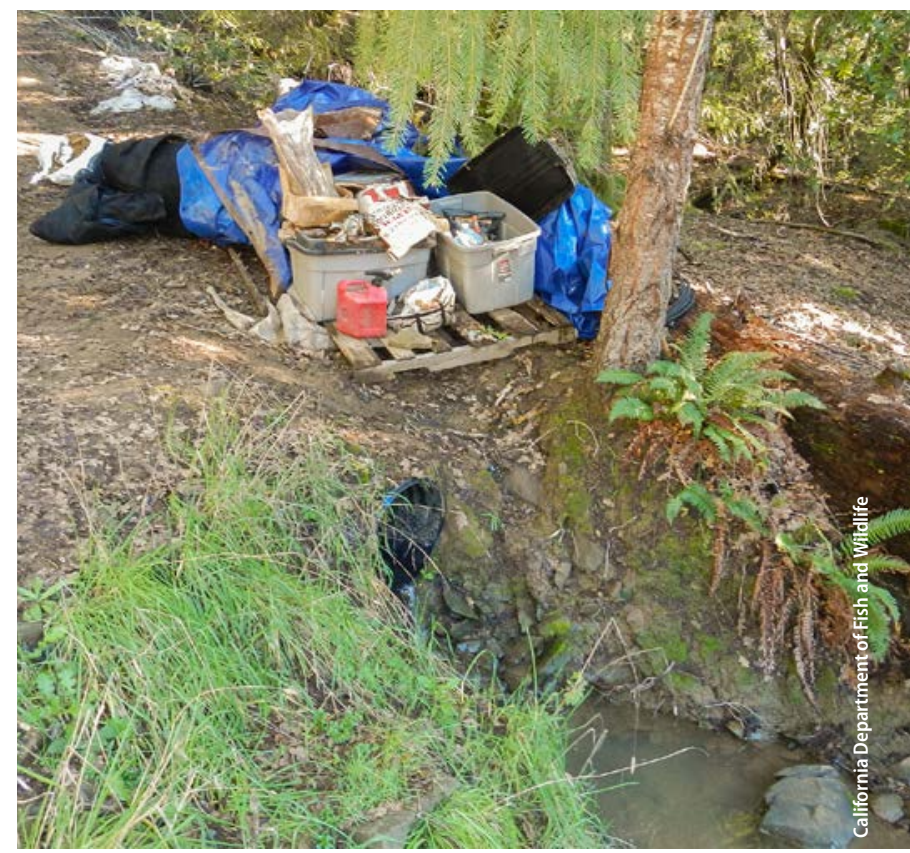




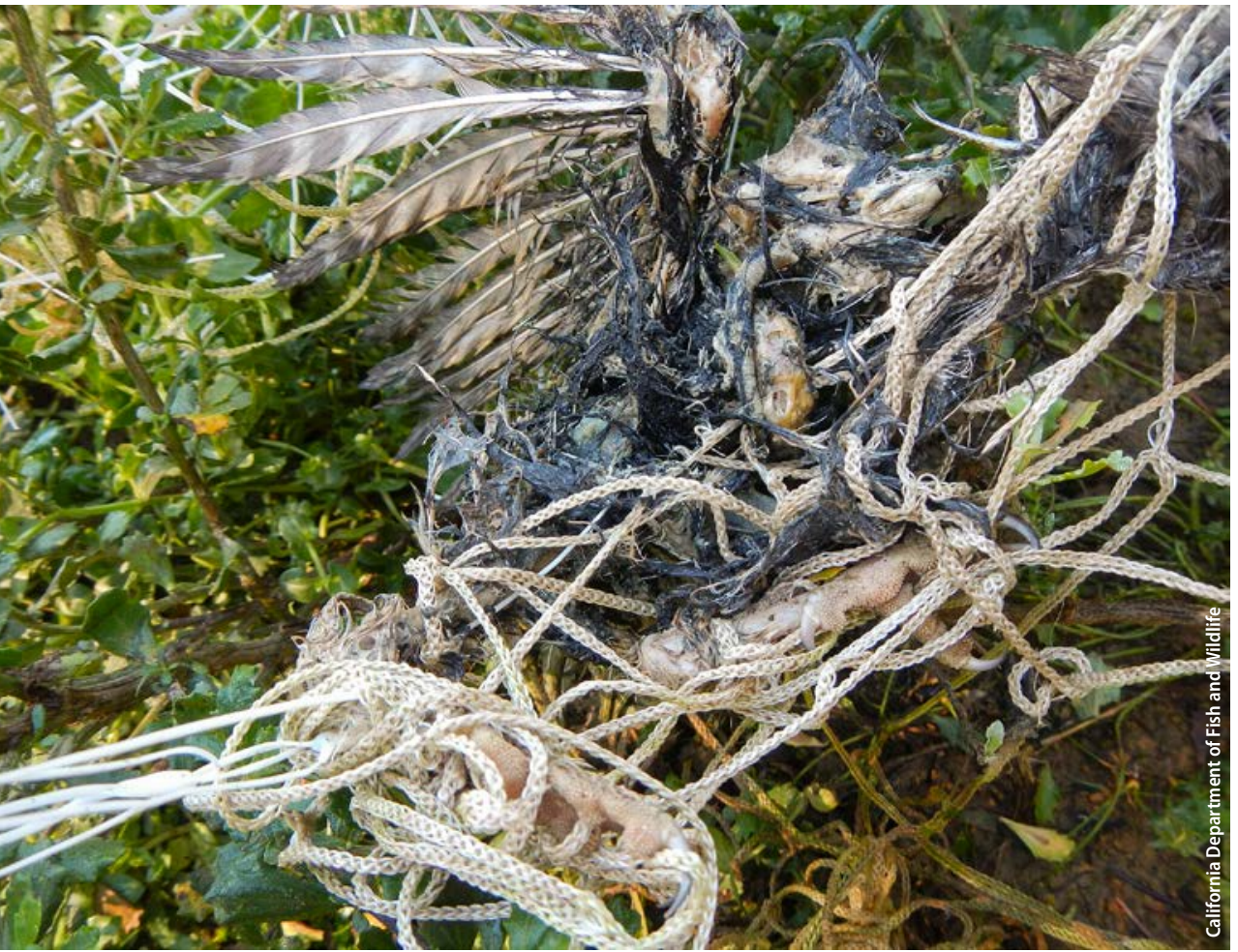

A Western screech owl trapped in netting at a noncompliant cannabis cultivation site. to do. It seems like the sites that we visit on enforcement actions still have violations - that's not changing. But I would say it's getting better, because more people are entering the system and getting permits. The trend is definitely better.

Growers becoming compliant is one force, but another possible force is more people growing cannabis - the "green rush" phenomenon. In your view, which is going faster? Are people coming into compliance faster than the overall rate of cannabis cultivation is growing?

I think that's a fair assumption - though we haven't done a deep analysis of that, and maybe the total acreage is still increasing across the state because we have other counties, besides the Emerald Triangle, entering the system. There are counties like Santa Barbara, with a huge, thriving cultivation scene that has added to the [overall] amount [of cultivation]. But in Humboldt County, we're seeing people leaving the system. They're done with cultivation. They've sent in their notices to the county to withdraw their applications. So what's the balance right now between Santa Barbara, with a bunch of new greenhouses, and Humboldt County, where people are leaving? It's safe to say that supply exceeds demand. That extra supply leaves the state through the black market. But I don't think, in general, there is a giant increase in cultivation across the state.
My impression, and it's nothing but an impression, is that law enforcement shows up at relatively few illegal cultivation sites. Who decides which sites get busted? How big a role does evidence of environmental harm play in those decisions?

What drives actions with all of our teams is a focus on natural resource impacts. That's our mission - to protect public trust resources for the state of California and its citizens - so we focus on where those impacts are. It's different in different places. In Humboldt, Trinity and Mendocino, we've got salmon and steelhead populations that we are trying to recover and protect. Protecting those species has been a big focus. But if you go down south, in the San Joaquin, it's a little different. You've got endangered critters like kangaroo rat and Mohave ground squirrels that are affected by cultivation in the desert. The focus in the south may be these endangered terrestrial animals whereas, up north, it's more aquatic - though we still look at issues around Northern spotted owl and the [Pacific] fisher. We're trying to focus our enforcement efforts on important areas that will conserve sensitive species, and every year we're more efficient. People tend to think we don't get to much. But, partnering with local law enforcement and others, we've been pretty effective. I think we've been doing a good job of protecting our sensitive plants and animals and fish.

What do you think is most likely to mitigate the environmental harms that are associated with illegal cannabis cultivation - more enforcement, bringing more growers into the legal market or something else I'm not thinking of?

I think it's a combination of all that. Getting people permitted, and abiding by the rules that are meant to protect our water quality and our native wildlife, is super important. But if you don't have an enforcement component, people tend to not follow the rules. You have to have both. I think we're achieving a good balance of that. We're permitting hundreds of sites and we're also doing enforcement. There's a balance there and I don't think either is more important than the other.

Are you optimistic that over the medium term - the next 5 or 10 years - that this issue of environmentally harmful cannabis cultivation sites can be brought well under control?

Absolutely. I really am. I'm hopeful that, in 5 years, it will be a much better situation. CA 